\title{
EDIFICAÇÕES DE ENERGIA ZERO: USO \\ DAS CORES COMO ESTRATÉGIA PARA A \\ REDUÇÃO DO CONSUMO DE ENERGIA
}

\section{ZEROENERGY BUILDINGS:USE OFCOLORS AS A STRATEGYTOREDUCEENERGY CONSUMPTION}

\author{
ARTUR MARTINS KAMIMURA | UFSC \\ VERÔNICA MARTINS GNECCO | UFSC \\ RAFAEL FERNANDO GIARETTA | UFSC \\ MICHELE FOSSATI, Dra. | UFSC
}

\begin{abstract}
RESUMO
Dado o aumento mundial do consumo energético em edificações, uma alternativa para minimizá-lo são as Edificações de Energia Zero (EEZ). Assim, estratégias para redução do consumo energético são necessárias, como a redução da absortância à radiação solar (ARS) da envoltória da edificação. Partindo de simulações termo energéticas para quatro cidades brasileiras - São Joaquim, Florianópolis, Teresina e Porto Velho - e da utilização de diferentes cores nas paredes e coberturas, com absortâncias de 30\%,60\% e 90\%, foram obtidos os consumos para condicionamento dos ambientes de uma edificação residencial. Calculou-se o percentual de redução de carga térmica de cada uma das soluções propostas, quando comparadas àquela de maior consumo em cada cidade. Observou-se que para os locais onde a demanda predominante é por resfriamento, ARS mais baixas são a melhor solução; o contrário vale para locais com demanda maior por aquecimento. Estimou-se ainda a redução da área de painéis fotovoltaicos resultante de cada solução, sendo Porto Velho a cidade que apresentou maior diminuição da área absoluta de painéis, $12,7 \mathrm{~m}^{2}$, a partir da redução de $39,5 \%$ da demanda energética para condicionamento. Nesse caso, a redução é proporcional àquela da carga térmica, mas também depende dos valores de irradiação solar de cada localidade.
\end{abstract}

PALAVRAS CHAVE: Absortância à radiação solar; Edificações de Energia Zero; Energia fotovoltaica; Cargas térmicas.

\begin{abstract}
Due to the increasing energy consumption of buildings worldwide, the Zero Energy Buildings (ZEB) are an alternative. Thus, strategies to reduce energy consumption are necessary. One of the strategies is to reduce the absorption to solar radiation (ARS) of the building envelope. From the thermo-energetic simulations of four Brazilian cities - São Joaquim, Florianópolis, Teresina and Porto Velho - and the use of different colors on the walls and roofs, with absorbances of $30 \%, 60 \%$ and $90 \%$, consumption for conditioning of the residential building environments. The percentage of thermal load reduction for each of proposed solutions was calculated, when compared to the one with the highest consumption in each city. It was observed that for locations where the predominant demand is cooling, lower ARS are the best solution; where the main demand is for heating, higher ARS values provide a reduction in the thermal load. The reduction in the area of photovoltaic panels resulting from each solution was also estimated, where Porto Velho presented $12,7 \mathrm{~m}^{2}$ of reduction, with $39,5 \%$ less energy consumption for conditioning. In this case, the reduction is proportional to the thermal load, but it also depends on the solar radiation values of each location.
\end{abstract}

KEY WORDS: Solar absorptance; Zero Energy Buildings, Photovoltaic energy; Thermal loads 


\section{INTRODUÇÃO}

Pouco mais da metade da eletricidade consumida no Brasil é utilizada nas edificações. Essa soma é dividida entre as edificações residenciais (25,4\%), comerciais $(16,9 \%)$ e públicas (8,2\%) (MME, 2019). Esse elevado percentual gera uma crescente preocupação quanto à melhoria da eficiência energética das edificações.

As edificações residenciais representam a maior porção desse consumo de energia elétrica e ainda apresentam tendência ao crescimento, de forma que o estudo dessa tipologia no contexto nacional e de edificações populares faz-se importante e necessário.

A partir desse contexto, busca-se estratégias para a redução do consumo energético de edificações, como por exemplo estratégias passivas e adequações na envoltória da edificação (RODRIGUEZ-UBINAS, 2014). A Absortância à Radiação Solar (ARS), mostra-se como uma solução com resultados muito relevantes quando se busca reduzir o consumo (BELUSSI et al., 2019). Para medição da influência das cores de paredes e coberturas, são indicadas as simulações energéticas, as quais envolvem modelagens térmicas dinâmicas que buscam aproximações da realidade em modelos computacionais (BORGSTEIN; LAMBERTS; HENSEN, 2018).

$A$ redução do consumo energético pode, ainda, viabilizar o projeto das Edificações de Energia Zero (EEZ), uma vez que a sua produção energética é renovável e local (TORCELLINI et al., 2006). Reduzir a quantidade de painéis fotovoltaicos, por exemplo, reduz também o custo para o proprietário da edificação.

Portanto, o objetivo deste artigo é analisar como o uso de diferentes cores (diferentes absortâncias à radiação solar) em paredes e coberturas pode afetar o consumo de energia para resfriamento e aquecimento de uma edificação, quando localizada em diferentes condições climáticas. Através desse estudo, será possível demonstrar como a escolha mais adequada das cores pode reduzir o consumo de eletricidade, dependendo do clima da região, e assim facilitar a implantação de Edificações de Energia Zero.

\section{REVISÃO BIBLIOGRÁFICA}

O consumo de energia aumentou substancialmente em edifícios na última década. Isso pode ser explicado pelo crescimento da população, pelo aumento da demanda de áreas edificadas e também por mudanças climáticas globais (UN ENVIRONMENT, 2017). Didoné, Wagner e Pereira (2014), apontam, todavia, que esse setor também possui grande potencial de economia de energia, por meio, por exemplo, de edificações que adotem estratégias de eficiência energética e tecnologias de geração local de energia.
Assim sendo, as Edificações de Energia Zero (EEZ), ou do inglês Zero Energy Buildings (ZEBs), mostram-se como uma alternativa viável e crescente para a redução do volume energético consumido por edifícios (CAO; DAl; LIU, 2016). A adoção mais ampla dessas edificações ocorre em países europeus e nos Estados Unidos, através da Diretiva do Parlamento Europeu sobre Eficiência Energética de Edifícios (EPBD) (EUROPEAN UNION, 2012), e do Ato de Segurança e Independência Energética de 2007 (US DEPARTMENT OF ENERGY, 2007), respectivamente.

Em termos gerais, as EEZ são edificações com consumos de energia minimizadas através da implementação de estratégias de eficiência energética e têm geração local por fonte renovável de tanta ou mais energia do que aquela consumida no período de um ano (TORCELLINI et al., 2006).

Dessa forma, no projeto de uma EEZ, existem dois fundamentos básicos: aplicação de medidas de eficiência energética e o uso de energia de fontes renováveis. A primeira questão está relacionada diretamente à envoltória da edificação, suas técnicas construtivas, soluções arquitetônicas ou pela inclusão de sistemas eficientes (BELUSSI et al., 2019). Alguns fatores que influenciam o desempenho energético das edificações, como o projeto arquitetônico, o clima local, os sistemas construtivos e suas propriedades térmicas, inclusive suas cores, são, portanto, importantes elementos a serem estudados, de forma que a demanda energética alimentada por fontes renováveis seja a menor possível (BRITO, AKUTSU, 2015).

Tratando especificamente dos materiais das envoltórias dos edifícios, sabe-se que os mesmos influenciam de forma significativa não só no ambiente urbano, mas também no conforto dos usuários e no consumo energético dos edifícios (SANTAMOURIS; SYNNEFA; KARLESSI, 2011).

Diversos estudos no Brasil analisaram as propriedades térmicas dos materiais das coberturas das edificações, sobretudo para investigar os efeitos da variação de sua coloração (BRITO; AKUTSU, 2015), dos tipos de cobertura (SILVEIRA; MARINOSKI; LAMBERTS, 2012; SILVA; ALMEIDA; GHISI, 2016; LIZ; ORDENES; GUTHS, 2018) ou envolvendo as duas análises anteriores (MUNIZ-GAAL et al., 2018).

Ainda, Santamouris, Synnefa e Karlessi (2011) verificaram que a escolha dos elementos construtivos da cobertura pode reduzir a demanda energética para resfriamento, além de influenciar positivamente no clima urbano do entorno, conclusões relevantes principalmente para países de clima quente. Muniz-Gäal et al., (2018) constataram grande sensibilidade da eficiência térmica dos materiais e cores empregados em uma cobertura. Um importante fator ligado ao desempenho térmico das coberturas 
e paredes é a absortância à radiação solar (ARS), muitas vezes negligenciada (SUEHRCKE; PETERSON; SELBY, 2008).

Outro fator que pode afetar o desempenho térmico das coberturas é o acúmulo de sujeira na superfície, alterando os valores de ARS, ocorrendo principalmente no primeiro ano de uso (MUNIZ-GAAL et al., 2018). Suehrke, Peterson e Selby (2008) concluíram que coberturas claras não mantêm sua ARS original. A pesquisa testou 13 amostras, que tiveram aumento da ARS de 12\% após três anos de uso, revelando a importância da manutenção periódica da edificação.

Da mesma maneira, as paredes, ainda que recebendo uma intensidade de incidência solar menor, também são sensíveis ao valor da ARS, como ilustrado em Silva, Almeida e Ghisi (2016), e em Barrios et al. (2012). Portanto, a ARS torna-se um fator de grande impacto no projeto de edifícios de alto desempenho energético, tais como os Edifícios de Energia Zero.

A absortância à radiação solar é definida pela NBR 15220-1 como o "quociente da taxa de radiação solar absorvida por uma superfície pela taxa de radiação solar incidente sobre esta mesma superfície" (ABNT, 2005a, p. 3). Faz necessário diferenciar este conceito de "absortividade", empregado erroneamente na literatura e tendo relação às propriedades específicas de materiais ou substâncias, enquanto absortância refere-se às propriedades de um corpo físico (DORNELLES, 2008).

Determina-se para a ARS que, quanto menor seu valor, mais clara a cor associada. Entretanto, segundo Dornelles (2008), o tipo de tinta utilizado também pode apresentar diferentes absortâncias: a rugosidade da tinta aumenta linearmente a absortância de cada superfície, sendo as amostras pintadas com tintas semi-brilho mais sensíveis às variações que as tintas foscas. $\mathrm{O}$ método e o equipamento utilizado para medição da absortância também deve ser levado em conta, uma vez que, naquele estudo, o procedimento com o espectrômetro ALTA II mostrou-se mais preciso e confiável.

Essa discussão é importante para esclarecer que a relação entre cor e absortância não é direta e depende de outros fatores, uma vez que cores são sensações visuais e que podem ter variações dependendo do observador. Como Newton comprovou, a radiação não tem cor, não sendo esses indicadores confiáveis de propriedades físicas de uma superfície (DORNELLES, 2008).

O CB3E (2015) estabelece uma relação entre refletância e absortância à radiação solar, sendo a soma das duas parcelas o total incidente na superfície, já que muitas vezes os valores tabelados não são exatos e o mais recomendado seria a medição das propriedades radiantes de cada superfície. A equação (1) demonstra o explicado:

$$
a=1-\rho
$$

Sendo:

$a=$ absortância à radiação solar;

$\rho=$ refletância solar.

Dornelles, Caram e Sichieri (2013) estudaram diferentes cores de tintas acrílicas, entre convencionais e refletivas, para pintura de coberturas e paredes. Após a medição da refletância solar, chegou-se à conclusão que a ARS afeta diretamente o desempenho térmico das superfícies pintadas e quanto menor a ARS for, menor a temperatura das superfícies do edifício. A pesquisa desenvolvida por Barrios et al., (2012), por sua vez, envolveu especificamente edifícios não condicionados, concluindo que a energia transferida pelas paredes ou coberturas depende das condições climáticas e da ARS. Essas condições climáticas têm importância na avaliação porque influenciam diretamente na energia transferida do exterior para o interior da edificação através da envoltória.

O estudo do processo decisório dos sistemas construtivos de uma edificação mostrou através de simulações computacionais que a transmitância e a ARS estão entre as variáveis mais determinantes do desempenho térmico e energético (SILVA; ALMEIDA, GHISI, 2016; SILVA; GHISI, 2019).

No setor residencial brasileiro, o aumento do consumo de energia elétrica para condicionamento do ar mais que triplicou entre 2005 e 2017, segundo a Empresa de Pesquisa Energética (EPE) (BRASIL, 2018), estimulado pelo crescimento de $9 \%$ no número de equipamentos nas residências no mesmo período.

O consumo cada vez mais representativo introduz o conceito de carga térmica, sendo, segundo a Proposta de Instrução Normativa Inmetro para a Classe de Eficiência Energética de Edificações Residenciais (INMETRO, 2018a), a quantidade de calor a ser fornecida ou retirada do ar para manter, em um ambiente, as condições desejadas, sendo de aquecimento ou resfriamento, respectivamente.

A produção de energia renovável e local pode ser realizada de diversas maneiras, como turbinas eólicas e sistemas de biomassa, entretanto a mais difundida é a geração fotovoltaica (LI; YANG; LAM, 2013; TORCELLINI et al., 2006). Os painéis fotovoltaicos, instalados sobre a cobertura (BAPV) gerar energia ocupando pouco espaço e de maneira integrada à arquitetura.

O Brasil possui ao longo de seu território um excelente potencial para a geração de energia fotovoltaica, onde os menores valores de incidência de radiação solar são ainda superiores àqueles presentes na Alemanha, país 
onde a implementação das tecnologias de geração de energia solar fotovoltaica são amplamente difundidas (CRONEMBERGER; CAAMAÑO-MARTíN; SÁNCHEZ, 2012)

Ao analisar o zoneamento bioclimático brasileiro, disposto na NBR 15220-3 (ABNT, 2005b), percebe-se que o Brasil é dividido em 8 zonas bioclimáticas. Este agrupamento facilita a identificação de particularidades regionais e a formulação de estratégias de eficiência energética para cada uma (RORIZ; GHISI; LAMBERTS, 2001). Nota-se, portanto, a importância de se analisar e demonstrar os efeitos do uso de diferentes cores em coberturas e paredes em diferentes condições climáticas brasileiras.

\section{MÉTODO}

Neste trabalho foram analisados os valores de carga térmica anual de resfriamento e aquecimento de uma edificação, quando situada em quatro cidades diferentes e com três variações de cores para coberturas e paredes. Para obtenção dos valores de carga térmica para resfriamento e aquecimento foram realizadas simulações computacionais por meio do software EnergyPlus, versão 9.2 (ENERGYPLUS, 2019). A modelagem da carga térmica anual de refrigeração e aquecimento foi realizada por meio do uso do grupo de objetos chamado de Ideal Loads Air System.

Como delimitações da pesquisa, não foram definidas cores específicas para a realização das análises, mas sim três valores de absortância comumente aplicáveis às cores mais claras, escuras e um valor intermediário entre elas. Admite-se, como explicado na seção de Revisão Bibliográfica, que cores não correspondem necessariamente a valores de absortância, dependendo ainda de outros fatores. Relativamente às simulações não foram considerados os efeitos da precipitação.

\subsection{Edificação analisada}

A edificação analisada deriva do trabalho de Montes (2016). A escolha deste modelo deu-se pelo fato de a edificação estudada ser representativa para edificações residenciais unifamiliares de baixa renda, visto que foi concebida pela autora a partir de um extenso banco de dados de projetos e de edificações reais. A Figura 1 ilustra a planta baixa e uma vista da edificação, que é composta por sala e cozinha conjugadas, dois dormitórios e um banheiro, totalizando $40 \mathrm{~m}^{2}$ de área construída.

O sistema construtivo mais utilizado atualmente em habitações de interesse social (HIS) no Brasil é o de paredes de concreto. No ano de 2016, 52\% das unidades habitacionais do Programa Minha Casa Minha Vida (PMCMV) foram construídas utilizando paredes de concreto; em 2015 esse sistema representava 36\% (ABCP, 2018). Para as coberturas, o sistema construtivo mais comum são as telhas de fibrocimento, presentes em cerca de metade do total de telhados no país, devido, sobretudo, ao seu baixo custo (COELHO; GOMEZ, DORNELLES, 2016). A partir disso, para a edificação analisada foram consideradas paredes de concreto e telhas de fibrocimento com forro de madeira.

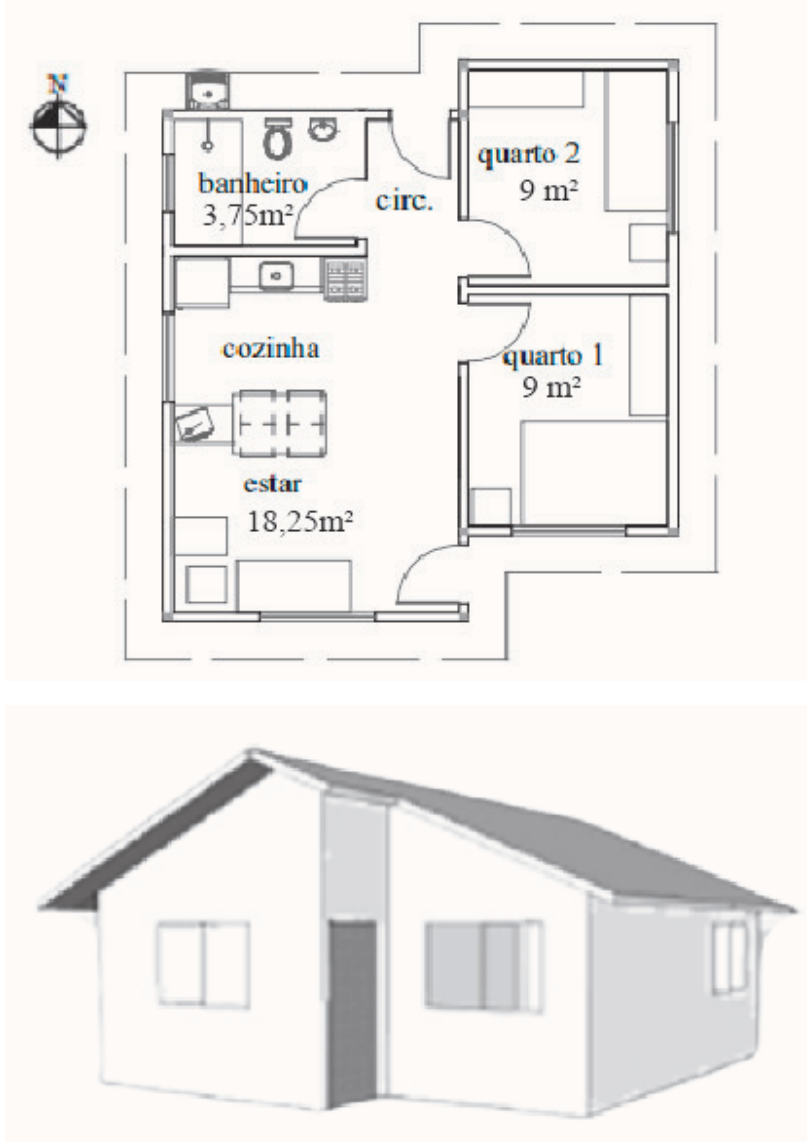

Figura 01 - Ilustração da edificação analisada Fonte: adaptado de Montes (2016)

Os vidros são do tipo simples de $3 \mathrm{~mm}$ nas aberturas, com fator solar de 0,87 e transmitância térmica de 5,7 W/m².K; as aberturas não possuem venezianas e nem projeção que proporcione sombreamento. As portas têm $30 \mathrm{~mm}$ de madeira, o piso tem estrutura de concreto e acabamento cerâmico.

\subsection{Considerações para as simulações}

A edificação descrita no item 3.1 foi simulada para as condições climáticas de quatro cidades brasileiras, considerando três valores diferentes de absortância à radiação solar para coberturas e paredes.

As cidades e zonas bioclimáticas escolhidas foram São Joaquim-SC (ZB1), Florianópolis-SC (ZB3), Teresina-PI (ZB7) e Porto Velho-RO (ZB-8). O objetivo com as escolhas 
foi abranger maior variedade de temperaturas médias anuais, compreendendo, nesse estudo, uma faixa que vai desde de $13,6^{\circ} \mathrm{C}$ em São Joaquim até $29,1^{\circ} \mathrm{C}$ em Teresina. Além disso, essas cidades apresentam potenciais de geração fotovoltaica bastante distintos, devido, sobretudo, às diferentes latitudes e condições de nebulosidade.

Foram definidos três valores de absortância à radiação solar para paredes e coberturas: 30, 60 e 90\%. Com isso tem-se um valor relativo a uma cor mais clara (30\%, próxima à cor branca), uma cor escura (90\%, próxima à cor preta) e um valor intermediário entre elas (60\%). As paredes foram nomeadas como par03, par06 e par09 e as coberturas como cob03, cob06 e cob09, respectivamente à absortância adotada.

O uso da ventilação natural foi considerado nos ambientes sempre que a temperatura do ar externo estivesse superior a $19^{\circ} \mathrm{C}$ e menor que a temperatura interna do ambiente. Ademais, utilizou-se do objeto Energy Management System do EnergyPlus para variar o acionamento do condicionamento artificial quando o ambiente estivesse ocupado e a ventilação natural não atendesse às temperaturas máximas e mínimas desejadas.

As cargas internas de equipamentos e iluminação foram consideradas apenas para a soma de energia dissipada no ambiente, mas seus consumos não foram considerados, já que o objetivo é analisar apenas a variação do consumo para aquecimento e resfriamento. As temperaturas para acionamento do condicionamento artificial e os padrões de ocupação seguiram o que preconiza a Proposta de Instrução Normativa Inmetro para a Classe de Eficiência Energética de Edificações Residenciais (INMETRO, 2018a), da seguinte forma:

- O consumo anual de energia para aquecimento (em kWh) é aquele necessário para aquecimento do ambiente durante o período compreendido entre $14 \mathrm{~h}$ e $22 \mathrm{~h}$ para as salas e durante o período compreendido entre $22 \mathrm{~h}$ e $08 \mathrm{~h}$ para os dormitórios. São consideradas duas pessoas por dormitório; duas pessoas por sala entre $14 \mathrm{~h}$ e $18 \mathrm{~h}$ e quatro pessoas por sala entre $18 \mathrm{~h}$ e $22 \mathrm{~h}$; todos os dias do ano, com termostato em $18^{\circ} \mathrm{C}$. O acionamento do sistema de aquecimento é realizado sempre que a temperatura operativa for inferior a $16^{\circ} \mathrm{C}$. A representação dessa ocupação está no Quadro 01, onde cada linha, em um tom diferente de cinza, simboliza uma pessoa.

- O consumo anual de energia para refrigeração (em kWh) é o consumo para refrigeração do ambiente considerando o mesmo padrão de ocupação descrito anteriormente, mas com termostato em $23^{\circ} \mathrm{C}$. O acionamento do sistema de refrigeração é realizado sempre que a temperatura operativa for superior a $260 C$.

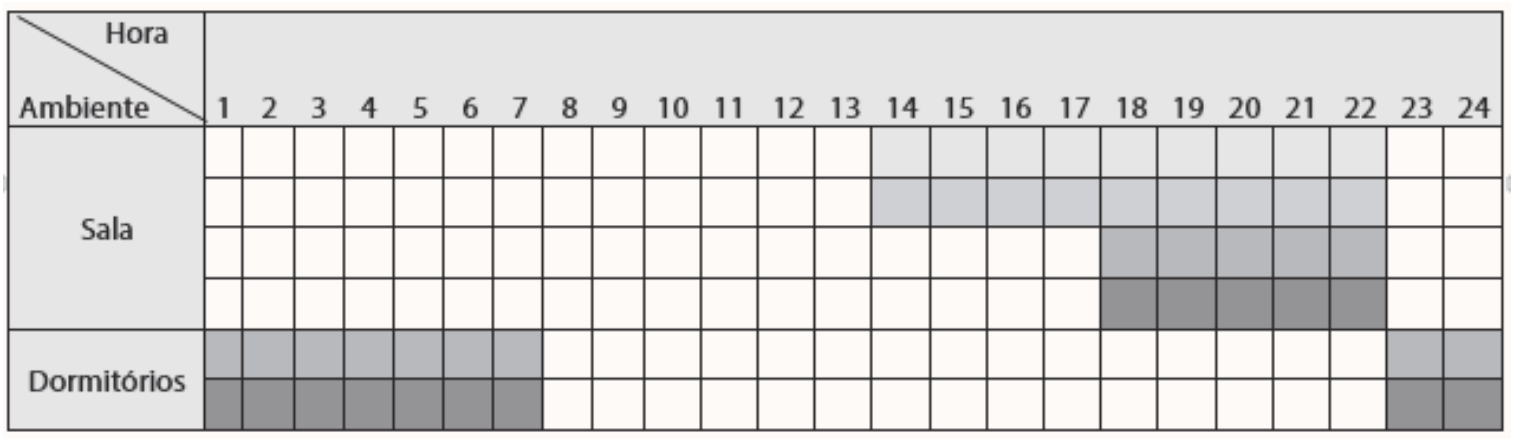

Quadro 01 - Representação dos horários de ocupação da sala e dos dormitórios Fonte: Autores.

\subsection{Análise da redução do consumo de eletrici- dade para condicionamento}

As análises comparativas entre as diferentes combinações de ARS foram feitas analisando as reduções de consumo para condicionamento da edificação.

Para a obtenção dos valores de consumo em kWh, os valores de carga térmica obtidos através das simulações computacionais foram divididos por um coeficiente de eficiência energética igual a 3,25. O valor foi escolhido pois o INMETRO exige um coeficiente de eficiência energética (CEE) maior que 3,23 em aparelhos de condicionamento de ar do tipo split para obtenção da classificação A na etiqueta de eficiência energética (INMETRO, 2018b).

Buscando demonstrar tendências nos comportamentos das edificações conforme o clima onde ela estiver inserida e as cores de suas coberturas e paredes, foram calculadas as reduções percentuais do total de carga térmica para condicionamento dos ambientes, sendo a soma das cargas para resfriamento e aquecimento. As reduções foram sempre comparadas à pior situação para cada cidade, ou seja, o caso base. A pior situação de cada cidade foi definida após a realização das simulações. 


\subsection{Análise da redução do uso de painéis fotovoltaicos}

A fim de demonstrar o potencial de cada estratégia no projeto de uma Edificação de Energia Zero, foi calculada qual seria a variação da área, em metros quadrados de painéis fotovoltaicos, resultante da redução de consumo em cada solução, quando comparadas ao pior caso (aquele de maior consumo) em cada cidade.

A geração estimada de eletricidade pelos painéis fotovoltaicos foi calculada multiplicando-se a irradiação média anual em cada localidade (corrigida para o plano inclinado em $30^{\circ}$, conforme o telhado, e orientado para leste), pelo rendimento do sistema e pela eficiência do painel fotovoltaico.

A geração média por metro quadrado foi tomada considerando os valores de irradiação solar média anual descritos no Atlas Solar Brasileiro (PEREIRA et al., 2017). Foi ainda considerado o rendimento do sistema de $76 \%$ (DGS, 2013) e um painel fotovoltaico com $17 \%$ e eficiência- valor médio encontrado para os painéis de silício multicristalino (FRAUNHOFER, 2019).

A geração estimada por metro quadrado de painel fotovoltaico, para as quatro cidades analisadas, está descrita na Tabela 01.

\begin{tabular}{|c|c|c|c|c|}
\hline & $\begin{array}{l}\text { Irradiação média anual no } \\
\text { plano inclinado }\left(\mathrm{kWh} / \mathrm{m}^{2} \text {. dia) }\right.\end{array}$ & $\begin{array}{l}\text { Rendimento do } \\
\text { sistema (\%) }\end{array}$ & $\begin{array}{l}\text { Eficiência do painel } \\
\text { fotovoltaico (\%) }\end{array}$ & $\begin{array}{l}\text { Geração estimada } \\
\left(\mathrm{kWh} / \mathrm{m}^{2} \text {. ano }\right)\end{array}$ \\
\hline São Joaquim & 4,23 & $76 \%$ & $17 \%$ & 199,5 \\
\hline Florianópolis & 4,05 & $76 \%$ & $17 \%$ & 191,0 \\
\hline Porto Velho & 5,31 & $76 \%$ & $17 \%$ & 250,4 \\
\hline Teresina & 5,45 & $76 \%$ & $17 \%$ & 257,0 \\
\hline
\end{tabular}

Tabela 01 - Potencial estimado de geração fotovoltaica Fonte: Autores.

\section{RESULTADOS E DISCUSSÃO}

\subsection{Análise da redução do consumo de eletrici-} dade para condicionamento

Nas Tabelas 02, 03, 04 e 05 são expostos os resultados obtidos para cada solução analisada, nas cidades de São Joaquim, Florianópolis, Porto Velho e Teresina, respectivamente. Nas tabelas, as soluções estudadas aparecem na ordem crescente de ARS para paredes e coberturas.
Nota-se que para Florianópolis, Porto Velho e Teresina a solução que proporcionou o melhor consumo foi a combinação de paredes e coberturas com cores cuja ARS é igual a 30\% (cores claras). Isso é justificado pelo fato de que o maior consumo nessas cidades é relativo ao resfriamento dos ambientes. Para a cidade de São Joaquim, onde o maior consumo é relativo ao aquecimento dos ambientes, a melhor solução (que apresentou menor consumo para condicionamento dos ambientes) é aquela cujas ARS de paredes e coberturas são iguais a $90 \%$.

\begin{tabular}{|c|c|c|c|c|c|c|c|c|c|}
\hline \multicolumn{10}{|c|}{ São Joaquim (valores em kWh/ano) } \\
\hline Medida & $\begin{array}{c}\text { Par03 + } \\
\text { Cob03 }\end{array}$ & $\begin{array}{c}\text { Par03 + } \\
\text { Cob06 }\end{array}$ & $\begin{array}{c}\text { Par03 }+ \\
\text { Cob09 }\end{array}$ & $\begin{array}{c}\text { Par06 }+ \\
\text { Cob03 }\end{array}$ & $\begin{array}{c}\text { Par06+ } \\
\text { Cob06 }\end{array}$ & $\begin{array}{c}\text { Par06+ } \\
\text { Cob09 }\end{array}$ & $\begin{array}{c}\text { Par09 + } \\
\text { Cob03 }\end{array}$ & $\begin{array}{c}\text { Par09 + } \\
\text { Cob06 }\end{array}$ & $\begin{array}{c}\text { Par09+ } \\
\text { Cob09 }\end{array}$ \\
\hline Resfriamento & 0,00 & 9,32 & 59,22 & 3,09 & 60,26 & 166,44 & 52,09 & 173,23 & 360,28 \\
\hline Aquecimento & 3726,20 & 3365,01 & 3067,02 & 3095,64 & 2793,42 & 2563,04 & 2581,69 & 2349,52 & 2157,91 \\
\hline $\begin{array}{c}\text { Carga térmica } \\
\text { total }\end{array}$ & 3726,20 & 3374,33 & 3126,24 & 3098,73 & 2853,68 & 2729,48 & 2633,78 & 2522,76 & 2518,19 \\
\hline Consumo & 1157,2 & 1047,9 & 970,9 & 962,3 & 886,2 & 847,7 & 817,9 & 783,5 & 782,0 \\
\hline \%Red & $0,0 \%$ & $-9,4 \%$ & $-16,1 \%$ & $-16,8 \%$ & $-23,4 \%$ & $-26,7 \%$ & $-29,3 \%$ & $-32,3 \%$ & $-32,4 \%$ \\
\hline $\mathrm{m}^{2}$ de painel & 0,0 & $-0,5$ & $-0,9$ & $-1,0$ & $-1,4$ & $-1,6$ & $-1,7$ & $-1,9$ & $-1,9$ \\
\hline
\end{tabular}

Tabela 02 - Percentual de redução de consumo em energia elétrica anual em São Joaquim Fonte: Autores. 


\begin{tabular}{|c|c|c|c|c|c|c|c|c|c|}
\hline \multicolumn{10}{|c|}{ Florlanopolis (valores em kWh/ano) } \\
\hline Medida & $\begin{array}{c}\text { Par03 }+ \\
\text { Cob03 }\end{array}$ & $\begin{array}{c}\text { Par03 }+ \\
\text { Cob06 }\end{array}$ & $\begin{array}{c}\text { Par03 }+ \\
\text { Cob09 }\end{array}$ & $\begin{array}{c}\text { Par06 + } \\
\text { Cob03 }\end{array}$ & $\begin{array}{c}\text { Par06 + } \\
\text { Cob06 }\end{array}$ & $\begin{array}{c}\text { Par06 + } \\
\text { Cob09 }\end{array}$ & $\begin{array}{c}\text { Par09 + } \\
\text { Cob03 }\end{array}$ & $\begin{array}{c}\text { Par09 + } \\
\text { Cob06 }\end{array}$ & $\begin{array}{c}\text { Par09 + } \\
\text { Cob09 }\end{array}$ \\
\hline Resfriamento & 3593,83 & 4639,52 & 5627,20 & 5312,02 & 6431,68 & 7525,49 & 7257,35 & 8509,12 & 9733,49 \\
\hline Aquecimento & 69,82 & 53,31 & 42,24 & 37,22 & 29,15 & 22,96 & 20,68 & 14,93 & 11,69 \\
\hline $\begin{array}{c}\text { Carga térmica } \\
\text { total }\end{array}$ & 3663,6 & 4692,8 & 5669,4 & 5349,2 & 6460,8 & 7548,5 & 7278,0 & 8524,0 & 9745,2 \\
\hline Consumo & 1137,8 & 1457,4 & 1760,7 & 1661,3 & 2006,5 & 2344,2 & 2260,3 & 2647,2 & 3026,5 \\
\hline \%Red & $-62,4 \%$ & $-51,8 \%$ & $-41,8 \%$ & $-45,1 \%$ & $-33,7 \%$ & $-22,5 \%$ & $-25 \%$ & $-13 \%$ & $0 \%$ \\
\hline $\mathrm{m}^{2}$ de painel & $-9,9$ & $-8,2$ & $-6,6$ & $-7,1$ & $-5,3$ & $-3,6$ & $-4,0$ & $-2,0$ & 0,0 \\
\hline
\end{tabular}

Tabela 03 - Percentual de redução de consumo em energia elétrica anual em Florianópolis Fonte: Autores.

\begin{tabular}{|c|c|c|c|c|c|c|c|c|c|}
\hline \multicolumn{10}{|c|}{ Porto Velho (valores em kWh/ano) } \\
\hline Medida & $\begin{array}{c}\text { Par03 }+ \\
\text { Cob03 }\end{array}$ & $\begin{array}{c}\text { Par03 }+ \\
\text { Cob06 }\end{array}$ & $\begin{array}{c}\text { Par03 }+ \\
\text { Cob09 }\end{array}$ & $\begin{array}{c}\text { Par06 + } \\
\text { Cob03 }\end{array}$ & $\begin{array}{c}\text { Par06 + } \\
\text { Cob06 }\end{array}$ & $\begin{array}{c}\text { Par06 + } \\
\text { Cob09 }\end{array}$ & $\begin{array}{c}\text { Par09 + } \\
\text { Cob03 }\end{array}$ & $\begin{array}{c}\text { Par09 }+ \\
\text { Cob06 }\end{array}$ & $\begin{array}{c}\text { Par09 + } \\
\text { Cob09 }\end{array}$ \\
\hline Resfriamento & 15672,16 & 17656,24 & 19350,00 & 19053,00 & 20977,18 & 22687,64 & 22335,96 & 24221,76 & 25909,30 \\
\hline Aquecimento & 0,00 & 0,00 & 0,00 & 0,00 & 0,00 & 0,00 & 0,00 & 0,00 & 0,00 \\
\hline $\begin{array}{c}\text { Carga térmica } \\
\text { total }\end{array}$ & 15672,2 & 17656,2 & 19350,0 & 19053,0 & 20977,2 & 22687,6 & 22336,0 & 24221,8 & 25909,3 \\
\hline Consumo & 4867,1 & 5483,3 & 6009,3 & 5917,1 & 6514,7 & 7045,9 & 6936,6 & 7522,3 & 8046,4 \\
\hline \%Red & $-39,5 \%$ & $-31,9 \%$ & $-25,3 \%$ & $-26,5 \%$ & $-19,0 \%$ & $-12,4 \%$ & $-13,8 \%$ & $-6,5 \%$ & $0,0 \%$ \\
\hline $\mathrm{m}^{2}$ de painel & $-12,7$ & $-10,2$ & $-8,1$ & $-8,5$ & $-6,1$ & $-4,0$ & $-4,4$ & $-2,1$ & 0,0 \\
\hline
\end{tabular}

Tabela 04 - Percentual de redução de consumo em energia elétrica anual em Porto Velho Fonte: Autores.

\begin{tabular}{|c|c|c|c|c|c|c|c|c|c|}
\hline \multicolumn{10}{|c|}{ Teresina (valores em kWh/ano) } \\
\hline Medida & $\begin{array}{c}\text { Par03 }+ \\
\text { Cob03 }\end{array}$ & $\begin{array}{c}\text { Par03 }+ \\
\text { Cob06 }\end{array}$ & $\begin{array}{c}\text { Par03 }+ \\
\text { Cob09 }\end{array}$ & $\begin{array}{c}\text { Par06 }+ \\
\text { Cob03 }\end{array}$ & $\begin{array}{c}\text { Par06 + } \\
\text { Cob06 }\end{array}$ & $\begin{array}{c}\text { Par06 + } \\
\text { Cob09 }\end{array}$ & $\begin{array}{c}\text { Par09 + } \\
\text { Cob03 }\end{array}$ & $\begin{array}{c}\text { Par09 + } \\
\text { Cob06 }\end{array}$ & $\begin{array}{c}\text { Par09 + } \\
\text { Cob09 }\end{array}$ \\
\hline Resfriamento & 18574,04 & 20335,54 & 21848,81 & 21588,45 & 23296,92 & 24829,55 & 24525,26 & 26229,52 & 27764,06 \\
\hline Aquecimento & 0,00 & 0,00 & 0,00 & 0,00 & 0,00 & 0,00 & 0,00 & 0,00 & 0,00 \\
\hline $\begin{array}{c}\text { Carga térmica } \\
\text { total }\end{array}$ & 18574,0 & 20335,5 & 21848,8 & 21588,4 & 23296,9 & 24829,5 & 24525,3 & 26229,5 & 27764,1 \\
\hline Consumo & 5768,3 & 6315,4 & 6785,3 & 6704,5 & 7235,1 & 7711,0 & 7616,5 & 8145,8 & 8622,4 \\
\hline \%Red & $-33,1 \%$ & $-26,8 \%$ & $-21,3 \%$ & $-22,2 \%$ & $-16,1 \%$ & $-10,6 \%$ & $-11,7 \%$ & $-5,5 \%$ & $0,0 \%$ \\
\hline $\mathrm{m}^{2}$ de painel & $-11,1$ & $-9,0$ & $-7,1$ & $-7,5$ & $-5,4$ & $-3,5$ & $-3,9$ & $-1,9$ & 0,0 \\
\hline
\end{tabular}

Tabela 02 - Percentual de redução de consumo em energia elétrica anual em Teresina Fonte: Autores.

4.2 Análise da redução da área de painéis fotovoltaicos

A redução da área de painéis fotovoltaicos proporcionada pela redução de consumo energético foi calculada para cada solução, em cada uma das cidades. O Gráfico 01 abaixo mostra a redução da área de painéis fotovoltaicos de acordo com cada solução proposta. Nota-se que, com exceção da cidade de São Joaquim, os valores relativos ao caso base (par09+cob09) não aparecem no gráfico, visto que sua redução é igual a zero. Para São Joaquim o valor de redução da combinação par03+cob03 foi zero. Pelo Gráfico 01, percebe-se ainda que a redução da área de painéis foi maior em climas mais quentes e amenos, uma vez que a redução da demanda nesses locais também foi maior. 
Pode-se dizer que a redução da área de painéis depende não só do clima da região, mas também da radiação solar incidente. Porto Velho, por exemplo, tem médias de temperaturas anuais e irradiação solar inferiores às de Teresina e obteve maior redução em termos de consumo e também maior redução em área de painéis fotovoltaicos. Quanto menor a geração por $\mathrm{m}^{2}$ de painel, maior será a redução em área resultante da diminuição do consumo energético. Os elevados valores de redução (por exemplo, $12,7 \mathrm{~m}^{2}$ entre o pior e o melhor caso para Porto Velho,) justificam-se pela grande diferença entre os valores de ARS entre o caso base e o melhor caso, que resultaram em mais de $38 \%$ de economia energética.

Gráfico 01 - Redução da área de painéis fotovoltaicos para cada solução Fonte: Autores.

\section{CONCLUSÃO}

A cor da cobertura e paredes de uma edificação residencial tem papel fundamental na resposta térmica dos ambientes. Em locais cuja maior demanda é por resfriamento, com menores valores de absortância à radiação solar (ARS) é possível reduzir significativamente os valores de carga térmica dos ambientes.

Em locais cuja maior demanda energética é para o aquecimento dos ambientes, valores mais altos de ARS favorecem a redução da carga térmica. Em locais com climas mais amenos e quentes, como Florianópolis, Porto Velho e Teresina a estratégia de variação ARS mostrou-se mais importante na redução de consumo.

Em São Joaquim a demanda para condicionamento foi menos impactada pela mudança das cores. Nesse caso, a demanda maior era para aquecimento e também a temperatura média anual é de $13,6^{\circ} \mathrm{C}$, sendo esse o local mais frio do Brasil. Ambos fatores podem ser motivo para o menor impacto da troca das cores da cobertura e das paredes na redução de cargas térmicas.

A área de painéis fotovoltaicos é reduzida quando a demanda de consumo por resfriamento ou aquecimento também diminuir. Essa redução depende fortemente de adaptações da edificação ao clima local, ou seja, de como o projeto da edificação incorpora estratégias para melhor se adaptar às condições climáticas locais, que podem demandar, a depender de suas características, maior consumo para resfriamento ou aquecimento

Dessa forma, ressalta-se como a consideração da ARS pode ser um importante elemento projetual visando a redução de consumo energético. Os resultados desse trabalho indicaram que a mudança desse elemento pode gerar importantes reduções de consumo e consequente redução de área de painéis fotovoltaicos para atender essa demanda. Com a adoção da combinação de ARS em paredes e coberturas mais adequada, foi possível a redução de $12,7 \mathrm{~m}^{2}$ de painéis fotovoltaicos em Porto Velho, quando comparado ao pior caso.

Portanto, ao projetar uma Edificação de Energia Zero (EEZ) com geração fotovoltaica, devem ser inicialmente levadas em conta as estratégias de eficiência energética mais adequadas. Com isso, os custos para implantação do sistema de geração de energia de uma EEZ podem ser menores e o projeto viabilizado. 
Sugere-se, para trabalhos futuros, que seja feita a análise de uma edificação implantada em uma maior quantidade de cidades e também com diferentes soluções construtivas associadas às mudanças de cores, de forma que se possa comparar mais precisamente o impacto da ARS na redução de cargas térmicas e na quantidade de painéis fotovoltaicos. Além disso, a validação dos efeitos da ARS sobre o consumo para condicionamento de edificações pode também ser feita através de estudos experimentais.

\section{REFERÊNCIAS}

ABCP - Associação Brasileira de Concreto Portland. Sistema de paredes de concreto Disponível em: <http://www.abcp.org.br/cms/wp-content/uploads/2018/02/Link2_cc3.pdf>

ABNT - ASSOCIAÇÃO BRASILEIRA DE NORMAS TECNICAS. NBR 15.575-1: Desempenho térmico de edificações: parte 1: definições, símbolos e unidades. Rio de Janeiro: ABNT, 2005a.

ABNT - ASSOCIAÇÃO BRASILEIRA DE NORMAS TECNICAS. NBR 15.575-3: Desempenho térmico de edificações: parte 3: Zoneamento bioclimático brasileiro e diretrizes construtivas para habitações unifamiliares de interesse social. Rio de Janeiro: ABNT, 2005b. BARRIOS, G., HUELSZ, G.; ROJAS, J.; OCHOA, J. M.; MARINCIC, I. Envelope wall/roof thermal performance parameters for non air-conditioned buildings. Energy And Buildings, [s.I.], v. 50, p.120-127, jul. 2012. Elsevier BV.

BELUSSI, L.; BAROZZI, B.; BELLAZZI, A.; DANZA, L.; DAVITOFRANCESCO, A.; FANCIULLI, C.; GHELLERE, M.; GUAZZI, G.; MERONI, I.; SALAMONE, F.; SCAMONI, F.; SCROSATI, C. A review of performance of zero energy buildings and energy efficiency solutions. Journal of Building Engineering, [s.I.], v. 25, p.2-21, set. 2019. Elsevier BV.

BORGSTEIN, E. H.; LAMBERTS, R.; HENSEN, J. L. M. Mapping failures in energy and environmental performance of buildings. Energy and Buildings, [s. I.], v. 158, p. 476-485, 2018. Disponível em: <http://dx.doi. org/10.1016/j.enbuild.2017.10.038>

BRASIL, EPE. Nota Técnica $\mathbf{n}^{\circ} \mathbf{0} \mathbf{3 0}$ de $\mathbf{1 3}$ de dezembro

de 2018. Uso de ar condicionado no Setor Residencial Brasileiro: Perspectivas e contribuições para o avanço em eficiência energética.

BRITO, A. C.; AKUTSU, M.. Contribuição da cor da cobertura na melhoria do desempenho térmico de habitação no período de verão. In: ENCAC, 8., 2015, Campinas. Anais.... Campinas: Unicamp, 2015. p. 2 - 10.
CAO, X.; DAI, X.; LIU, J. Building energy-consumption status worldwide and the state-of-the-art technologies for zero-energy buildings during the past decade. Energy and Buildings, [s. I.], v. 128, p. 198-213, 2016. Disponível em: <http://dx.doi.org/10.1016/j. enbuild.2016.06.089>

CB3E. Guia de medição e cálculo para refletância e ARS em superfícies opacas. Florianópolis: LabEEE, 2015. $23 \mathrm{p}$.

COELHO, T. C. C.; GOMES, C. E. M.; DORNELLES, K. A.. Desempenho térmico e ARS de telhas de fibrocimento sem amianto submetidas a diferentes processos de envelhecimento natural. Ambiente Construído, [s.l.], v. 17, n. 1, p.147-161, mar. 2017. FapUNIFESP (SciELO). CRONEMBERGER, J.; CAAMAÑO-MARTÍN, E.; SÁNCHEZ, S. V. Assessing the solar irradiation potential for solar photovoltaic applications in buildings at low latitudes - Making the case for Brazil. Energy and Buildings, [s. I.], v. 55, p. 264-272, 2012.

DGS - German Solar Energy Society. Planning and Installing Photovoltaic Systems. 2013.

DIDONÉ, E. L.; WAGNER, A.; PEREIRA, F. O. R. Estratégias para edifícios de escritórios energia zero no Brasil com ênfase em BIPV. Ambiente Construído, Porto Alegre, v. 14, n. 3, p. 27-42, jul./set. 2014.

DORNELLES, K. A.; CARAM, R. M.; SICHIERI, E. P. ARS e desempenho térmico de tintas frias para uso no envelope construtivo. Paranoá: Cadernos de Arquitetura e Urbanismo, [s.l.], n. 12, p.55-64, 31 dez. 2013. Programa de Pos-Graduacao em Arquitetura e UrLbanismo Univ. de Brasilia.

DORNELLES, K. A. Absortância solar de superfícies opacas: métodos de determinação base de dados para tintas látex acrílica e PVA. 2008. 160p. Tese (Doutorado) - Faculdade de Engenharia Civil, Arquitetura e Urbanismo, Universidade Estadual de Campinas, Campinas, 2008.

ENERGYPLUS. EnergyPlus. Disponível em: < https:// energyplus.net/> .

EUROPEAN UNION. Directive 2012/27/EU of the European Parliment and of the council of 25 October 2012 on energy efficiency. Disponível em: <https://eur-lex.europa.eu/legal-content/EN/TXT/ PDF/?uri=CELEX:32012L0027\&from=EN>

FRAUNHOFER. Photovoltaics Report 2019 from FRAUNHOFER INSTITUTE FOR SOLAR ENERGY SYSTEMS. Disponível em: https://www.ise.fraunhofer. de/content/dam/ise/de/documents/publications/studies/Photovoltaics-Report.pdf. 
INMETRO - INSTITUTO NACIONAL DE METROLOGIA, QUALIDADE E TECNOLOGIA. Proposta de Instrução Normativa INMETRO para a Classe de Eficiência Energética de Edificações Residenciais. Florianópolis: INMETRO, 2018a.

INMETRO. Tabelas de eficiência energética. 2018b. Disponível em: <http://www.inmetro.gov.br/consumidor/pbe/condicionadores_ar_split_hiwall_indicenovo.pdf $>$.

LI, Danny H. W.; YANG, Liu; LAM, Joseph C. Zero energy buildings and sustainable development implications A review. Energy, [s. I.], v. 54, p. 1-10, 2013. Disponível em: <http://dx.doi.org/10.1016/j.energy.2013.01.070>

LIZ, D.S.; ORDENES, M.; GUTHS, S. Análise experimental do comportamento térmico do telhado verde extensivo para Florianópolis. Oculum Ensaios, v.15, n.2, p.315-333, 2018.

MINISTÉRIO DE MINAS E ENERGIA - MME. Balanço Energético Nacional 2019. Disponível em: http:// www.epe.gov.br/pt/publicacoes-dados-abertos/ publicacoes/balanco-energetico-nacional-2019.

MONTES, M. A. T. Abordagem Integrada no Ciclo de Vida de Habitação de Interesse Social Considerando Mudanças Climáticas. 2016. 473 f. Tese (Doutorado) - Curso de Engenharia Civil, Universidade Federal de Santa Catarina, Florianópolis, 2016.

MUNIZ-GÄAL, L. P.; PEZZUTO, C. C.; CARVALHO, M. F. H.; MOTA, L. T. M. Eficiência térmica de materiais de cobertura. Ambiente Construído, [s.I.], v. 18, n. 1, p.503-518, mar. 2018. FapUNIFESP (SciELO).

PEREIRA, E.; MARTINS, F. R.; GONÇALVES, A. R.; COSTA, R. S.; LIMA, F. J. L.; RÜTHER, R.; ABREU, S. L.; TIEPOLO, G. M.; PEREIRA, S. V.; SOUZA, J. G. Atlas Brasileiro de Energia Solar - 2a Edição. 2. ed. São José dos Campos: INPE, 2017

RODRIGUEZ-UBINAS, Edwin; MONTERO, C.; PORTEROS, M.; VEGA, S.; NAVARRO, I.; CASTILLO-CAGIGAL, M.; MATALLANAS, E.; GUTIERREZ, A.. Passive design strategies and performance of Net Energy Plus Houses. Energy and Buildings, [s. I.], v. 83, p. 10-22, 2014.

RORIZ, M.; GHISI, E.; LAMBERTS, R. Um Zoneamento Bioclimático Para a Arquitetura no Brasil. In: Jornada sobre Clima e Aplicação na Comunidade de Países de Língua Oficial Portuguesa, 2., Maceió, AL, 2001. Anais... Maceió: UFAL, 2001. p. 1-7.

SANTAMOURIS, M.; SYNNEFA, A.; KARLESSI, T. Using Advanced Cool Materials in the Urban Built Environment to Mitigate Heat Insland and Improve
Thermal Comfort Conditions. Solar Energy, v. 85, n. 12, p. 3085-3102, 2011.

SILVA, A. S.; GHISI, E.. Estimating the sensitivity of design variables in the thermal and energy performance of buildings through a systematic procedure. Journal Of Cleaner Production, [s.I.], v. 244, p.1-19, jan. 2019. Elsevier BV.

SILVA, A.S.; ALMEIDA, L. S. S.; GHISI, E. Decision-Making Process for Improving Thermal and Energy Performance of Residential Buildings: A Case Study of Constructive Systems in Brazil. Energy and Buildings, v.128, n.18, p.270-286, 2016.

SILVEIRA, R.; MARINOSKI, D. L.; LAMBERTS, R. Avaliação da Absortância à Radiação Solar e Temperatura Superficial de Telhas de Fibrocimento Utilizadas nas Coberturas de Edificações do Campus da UFSC. In: ENCONTRO NACIONAL DE TECNOLOGIA DO AMBIENTE CONSTRUÍDO, 14., Juiz de Fora, 2012. Anais... Juiz de Fora, 2012.

SUEHRCKE, H.; PETERSON, E. L.; SELBY, N.. Effect of roof solar reflectance on the building heat gain in a hot climate. Energy And Buildings, [s.I.], v. 40, n. 12, p.22242235, jan. 2008. Elsevier BV.

TORCELLINI, P.; PLESS, S.; DERU, M.. Zero Energy Buildings: A Critical Look at the Definition. ACEEE Summer Study Pacific Grove, [s. I.], p. 15, 2006. Disponível em: <http://www.nrel.gov/docs/fy06osti/39833.pdf>

US DEPARTMENT OF ENERGY. Energy Independence and Security Act of 2007. Washington Dc: Doe/ee, 2007.

UN Environment and International Energy Agency (2017): Towards a zero-emission, efficient, and resilient buildings and construction sector. Global Status Report 2017.

\section{AGRADECIMENTOS}

O presente trabalho foi realizado com apoio da Coordenação de Aperfeiçoamento de Pessoal de Nível Superior - Brasil (CAPES) - Código de Financiamento 001. 


\section{AUTORES}

ORCID: https://orcid.org/0000-0002-3496-4153

ARTUR MARTINS KAMIMURA | Universidade Federal de Santa Catarina | Programa de Pós-Graduação em Arquitetura e Urbanismo | Florianópolis, SC - Brasil | Correspondência para: R. Eng. Agronômico Andrei Cristian Ferreira, 662 Carvoeira, Florianópolis - SC

ORCID: https://orcid.org/0000-0002-5473-5075

VERÔNICA MARTINS GNECCO | Universidade Federal de Santa Catarina | Programa de Pós-Graduação em Arquitetura e Urbanismo | Florianópolis, SC - Brasil | Correspondência para: R. Eng. Agronômico Andrei Cristian Ferreira, 662 Carvoeira, Florianópolis - SC

ORCID: https://orcid.org/0000-0002-6243-3114

RAFAEL FERNANDO GIARETTA | UFSC | Arquitetura e Urbanismo | Florianópolis, SC - Brasil | Correspondência para: R. Eng. Agronômico Andrei Cristian Ferreira, 662 - Carvoeira, Florianópolis - SC

ORCID: https://orcid.org/0000-0001-6989-5381

MICHELE FOSSATI, ENGENHEIRA CIVIL, Dra. | Universidade Federal de Santa Catarina | Engenharia Civil| Florianópolis, SC Brasil | Correspondência para: R. Eng. Agronômico Andrei Cristian Ferreira, 662 - Carvoeira, Florianópolis - SC

\section{COMO CITAR ESTE ARTIGO}

KAMIMURA, Artur Martins; GNECCO, Verônica Martins; GIARETTA, Rafael Fernando; FOSSATI, Michele. Edificações de Energia Zero: Uso das Cores como Estratégia para a Redução do Consumo de Energia. MIX Sustentável, [S.I.], v. 6, n. 2, p. 99-110, mai. 2020. ISSN 24473073. Disponível em:<http://www. nexos.ufsc.br/index.php/mixsustentavel>. Acesso em: dia mês. ano. doi:https://doi.org/10.29183/2447-3073. MIX2020.v6.n2.99-110. 
